\title{
LOPE ENTRE DOS MUNDOS
}

Hablar del realismo de la literatura española ha llegado a ser un lugar común, a tal punto que su sola mención ya suena a tópico. Pero los tópicos, como ideas venidas a menos que realmente son, han embotado sus aristas significativas al rodar de mano en mano, y andan así de rebote por el mundo, informes y desustanciados de la carga original de sentido que hayan podido tener. Así, en la actualidad, cuando se habla de realismo no sabe uno a qué carta quedarse, tanto se ha desdibujado el perfil de esa incómoda palabra realismo.

Sea como sea, allí está consagrada en los manuales, y ya no la sacará de ese infierno literario ni el propio redivivo Orfeo con su lira. La literatura de los siglos de oro es, quizá, la que más ha sufrido por esa canonización del realismo, y pocos son los autores cuyas obras no se han visto medidas por ese cartabón. Si algo se ha salvado de este tipo de "letrimensura" han sido autores y géneros de trasmano y a contrapelo de nuestra sensibilidad, como las novelas caballerescas o pastoriles. Lo demás, casi todo está empadronado y rubricado, a las buenas o a las malas, como literatura realista, desde Juan del Encina y Fernando de Rojas hasta Cervantes y Lope de Vega.

Ya lanzados por este camino, se ha llegado a considerar la obra literaria como documento histórico fehaciente, y las obras de Cervantes, Lope, Ruiz de Alarcón, o bien la casi desconocida doña Mariana de Carbajal y Saavedra, han venido a servir de minero documental. En esta actitud, me inquieta sobremanera la supeditación jerárquica que ella implica de la imaginación a la realidad, aunque mucho más, de seguro, se inquietarían los artistas en cuestión. En resumidas cuentas: ante la mágica palabra realismo se han avasallado todas las otras posibles cualidades diferenciadoras, y nos hemos quedado con una literatura pauperizada por su supuesta aspiración a crear - o recrear - realidades canónicas.

Las razones para esta desvirtuación del quehacer crítico son evidentes. Téngase en cuenta que la crítica literaria nace en el siglo XIX bajo constelación de realismo, y en consecuencia no hace 
más que recrear el pasado a su imagen. Esto es efecto natural de la vis retroactiva que tiene la realidad, pero lo cierto es que la historia literaria ha venido repitiendo la imagen del pasado que formó la realidad histórica del siglo xix.

Por fortuna, críticos zahoríes han visto a través de esta armazón ideológica decimonónica, que compendiaba los mayores logros literarios del pasado en la aspiración a realismo, y han empezado a sonar las voces de alarma, que se repiten dia a día con creciente y saludable vigor. Entre los buenos, la literatura española ya no se considera más como un plácido mar que sólo refleja pasivamente la realidad circundante, sino más bien como una pleamar cuyo oleaje se rompe ante los promontorios de Escila y Caribdis, según la certera imagen de Dámaso Alonso. Escila y Caribdis de la literatura española, ese sistema de polaridades que culmina en la dualidad realismo-idealismo, en la que estos términos no se cancelan ni jerarquizan, sino se complementan como los polos eléctricos.

En ese juego de dualidades se ha empezado a dibujar con más preciso contorno la silueta de la realidad literaria de la España áurea, aunque, fuerza es decirlo, queda mucho por hacer. Porque, entre otras razones, la crítica moderna, en muchos casos, incurre en el error de creer que con darle nombre a una cosa nos informan sobre ella. Una de las más insignes víctimas de la manía onomástica ha sido Lope de Vega, cuya inmensa obra ha sido encasillada bajo todas las rúbricas imaginables... y varias más. Con esto, lo único que se ha demostrado paladinamente es que la verdadera obra de arte siempre suma más que el conjunto de sus interpretaciones posibles.

En el caso de Lope, y por el solo tamaño de su obra, todo esto adquiere evidencia casi visual. Una de las operaciones críticas más practicadas con su producción literaria ha sido, precisamente, la que la escinde en dos mitades desiguales, una, que se lleva la parte del león, marcada obras realistas, con las comedias en lugar de privilegio, y la otra, de menores proporciones, intitulada obras idealistas, con listas variables, para diversos gustos. Así y todo, por allí suelen quedar, como el alma de Garibay, vagando entre cielo y tierra, algunas obras suyas reacias a esa taxología. Muy en especial las novelas: tres mayores -si contamos la Dorotea, que hasta en su sino crítico constituye excepción- y cuatro menores, a las que apenas si hay crítico que se acerque. Quizá la propia radiación de estas obras del foco del interés común fue el aliciente inicial para escribir estas páginas, llevado, tal vez, por ese insaciable pedir cotufas en el golfo que movió hasta al taciturno Rocinante. El hecho es que de estas flores del jardín de Lope he hecho ramillete con las más humildes, esas cuatro novelitas que el Fénix lanzó al mundo huérfanas hasta de título colectivo. 
Esas cuatro novelitas son conocidas en la actualidad con el título de Novelas a Marcia Leonarda, como si fueran volumen independiente, pero eš́o da una impresión errónea, muy distinta de las circunstancias reales de su aparición. En el año 1621 Lope había llegado a la cumbre de la fama, había entrado en órdenes después de enviudar por segunda vez, y se había encendido en su pecho ahincada pasión otoñal por Marta de Nevares - "Yo estoy perdido, si en mi vida lo estuve por alma y cuerpo de mujer", escribe a su protector-confidente, el duque de Sessa. En ese año Lope publica un volumen misceláneo, La Filomena, en el que incluye una novelita (Las fortunas de Diana) dedicada a Marcia Leonarda, seudónimo de su amante Marta de Nevares. Este intento de novelar a la italiana (o a la cervantina, según se verá) no fue segundado hasta 1624, cuando en otro tomo misceláneo, La Circe, Lope incluyó al finai tres novelitas, también dedicadas a su amante: La desdicha por la honra, La prudente venganza y Guzmán el Bravo. Y con esto el Fénix dejó de escribir novelas, al menos con la forma novelística usual, ya que, por lo demás, le quedaba nada menos que la Dorotea en el tintero.

Ha sido la erudición indiscreta la que ha dado unidad y autonomía a estas cuatro obritas, enlazándolas con el título colectivo de Novelas a Marcia Leonarda. Esto tergiversa la intención al parecer modesta de Lope, de insertarlas a la callada al final de obras de mayor envergadura, para dar la impresión, quizá, de que estas novelitas, como sus romances, "nacen al sembrar los trigos". Pero a Lope siempre le cuadró mal la actitud de modesto recato, y así, en el pórtico de la primera novelita, inscribió estas palabras, en las que no se disimula mucho la mala intención:

En España... también hay libros de novelas, dellas traducidas de italianos, y dellas proprias, en que no faltó gracia ni estilo a Miguel Cervantes. Confieso que son libros de grande entretenimiento y que podrian ser ejemplares, como algunas de las historias trágicas del Vandelo, pero habian de escribirlos hombres científicos, o por lo menos grandes cortesanos, gente que halla en los desengaños notables sentencias y aforismos.

Hombres cientificos, grandes cortesanos, notables sentencias: no, evidentemente el pobre Cervantes no cumplía ninguno de estos requisitos. Apenas si acertó, como el burro flautista, a que en las Novelas ejemplares no le faltase "gracia ni estilo". Muy en dómine escribe esto Lope - ¿por qué no, si quizá ya se diría por los mentideros "Creo en Lope todopoderoso, poeta del cielo y de la tierra"? De maestro a discípulo aventajado, así se deben plantear sus relaciones con Cervantes, o al menos, así se pueden plantear, cinco años después de la muerte de éste. Curiosa actitud la que adopta 
Lope: por un lado hurta el bulto a la comparación directa con las Novelas ejemplares de Cervantes por la forma de presentar las suyas al público; por el otro, hay una firme actitud de supcrioridad que invita a la comparación.

No creo pasarme de suspicaz al suponer que Lope, con este tipo de afirmaciones y nueva manera de concebir las dotes del novelista, aspiraba a ser para la corte literaria de Felipe IV - que acababa de ser coronado- lo que Cervantes había sido para la corte literaria de Felipe III. Son estos, precisamente, los años en que arrecia la ambición de Lope de ser nombrado cronista real, ¿y por qué no ser también novelista real, plaza no oficial pero vacante? Sería, sin embargo, un error estrechar demasiado las comparaciones entre los dos ingenios, ya que las diferencias son mayores que los parecidos. Considérese primero la deliberada diferencia de marco general entre Novelas ejemplares y Novelas a Marcia Leonarda. Cervantes dedica el cuerpo de sus doce obritas al conde de Lemos, y dialoga en público así con la más alta nobleza del reino, sobre materias que él considera ejemplares. Lope dirige sus desunidas novelitas de esquiva presencia a su amante Marcia Leonarda - situación poco ejemplar, por lo pronto-, y así dialoga en privado con ella, al abrigo de la escondida forma con que salen a luz. La elección de destinatario modula ya la naturaleza y el tono del diálogo, puesto que Lope, en conversación con su amante, se puede permitir un sinnúmero de libertades que no tendrían cabida si dialogase con la grandeza del reino. Si unimos a esto el deliberado descoyuntamiento en la presentación de esas cuatro novelitas, se perfila como posible motivo de todo ello la conciencia, por parte de Lope, de la necesidad de una mayor libertad de acción y amplitud de marco que en el caso cervantino. Si se aceptaban los supuestos formales de las Novelas ejemplares, no cabía más avance en el campo de la creación de realidades artísticas.

Desde un punto de vista de contenido, las novelitas tratan de crearse una órbita independiente de las Novelas ejemplares, aunque lo que logran, la verdad sea dicha, es crearse una órbita extravagante. Así, Las fortunas de Diana, que tiene algún paralelo con La señora Cornelia de Cervantes, apura las coincidencias y desdichas en ese juego característico de Lope de intimidar la verosimilitud con desplantes de ingenio. La desalicha por la honra tiene esa vida anfibia, hispanoárabe, propia de las historias de cautivos, que Lope imagina con virtuosismo, mientras que Cervantes la recrea con simpatía cordial. La prudente venganza nos lleva al mundo exorbitante de las tragedias de honor, y merece atención especial que le daré de inmediato. Guzmán el Bravo se parece de lejos a aquellas idealizaciones juveniles del Lope del romancero nuevo, en que él se nos presenta con toda la policromía del mundo moro. 
Me detendré un momento en La prudente venganza, cuyo desenlace y moralización final han provocado el irónico escepticismo de Marcel Bataillon, maestro de hispanistas. El marido agraviado mata con estudiado sigilo a todos los partícipes en su deshonra, ocasión en la que Lope amonesta:

He sido de parecer siempre que no se lava bien la mancha de la honra del agraviado con la sangre del que le ofendió, porque lo que fue no puede dejar de ser, y es desatino creer que se quita, porque se mata el ofensor, la ofensa del ofendido. Lo que hay en esto es que el agraviado se queda con su agravio y el otro muerto, satisfaciendo los deseos de la venganza, pero no las calidades de la honra, que para ser perfecta no ha de ser ofendida. ¿Quién duda que está ya la objeción a este argumento dando voces? Pues aunque tácita, respondo que no se ha de sufrir ni castigar; pues ¿qué medio se ha de tener? El que un hombre tiene cuando le ha sucedido otro cualquiera género de desdicha: perder la patria, vivir fuera della donde no le conozcan, y ofrecer a Dios aquella pena, acordándose que le pudiera haber sucedido lo mismo si en alguno de los agravios que ha hecho a otros le hubieran castigado; que querer que los que agravió le sufran a él, y él no sufrir a nadie, no está puesto en razón; digo sufrir, dejar de matar violentamente, pues por sólo quitarle a él la honra, que es una vanidad del mundo, quiere él quitarlos a Dios si se les pierde el alma.

El indignado tono del moralista encubre una peculiarisima ética, que en su formulación última sería algo por el estilo de "la deshonra recíproca requiere el perdón mutuo". ¡Valiente evangelismo el de Lope!, se ha exclamado. Y con razón, si dejásemos las cosas así. Pero tomémoslas de un poco más atrás y llevémoslas un poco más adelante, y se verá cómo esta extraña ética - hasta cínica, si se quiere-, se vertebra hasta dar una actitud consecuente, que si bien empieza como ademán retórico termina siendo el sostén y consuelo de la cansada vida del Fénix.

Ya en El peregrino en su patria (1604), Lope había presentado situación parecida, aunque de muy distinto desenlace. En el libro III de esta novela se nos dice cómo Pánfilo, el protagonista, ha deshonrado a Celio raptando a su hermana. Poco después, en acción recíproca, Celio rapta a la hermana de Pánfilo. Cuando éste se entera de su deshonra no se arroja a la venganza, sino que perdona a su ofensor. Aquí está, vitalizado por el arte de Lope, el tema concreto de la larga amonestación de años después. $\mathrm{Y}$ algo de este mismo espíritu pseudo-evangélico se infunde en esta curiosa apostilla que Lope puso a su largo poema épico, la Jerusalén conquistada (1609): "Nota que quita Dios el honor a los que le quitan a sus prójimos" (libro IX).

Todo esto suena a justificación ante el tribunal de su propia 
conciencia, y Lope aboga por el perdón mutuo del adulterio, el rapto o la deshonra en general, por el expediente de inyectar en el mensaje de la ética cristiana la carga emocional de sus propias vivencias de adúltero y raptor. Desde luego, nada de esto podría haber salido a las tablas, a enfrentarse con los mosqueteros de los corrales de comedias, sin correr riesgo propincuo de "que se les ofreciese ofrenda de pepinos, ni de otra cosa arrojadiza", según la frase de Cervantes. El español había creado una imagen de sí mismo, centrada en el concepto del honor, tan monolítica y trascendente como la que había proyectado de su idea de imperio por los cuatro costados del mundo. Con el honor no cabían claudicaciones de ningún tipo, al menos en público. Pero el recogimiento de la lectura ofrecía la oportunidad de dialogar a solas con el lector, y Lope se podía permitir el lujo de descorrer un poco más el velo de la intimidad de su pensamiento, más aún en diálogo con su amante y cómplice de adulterio.

Al inyectar en el precepto ético la carga de sus vivencias, Lope puede desarrugar la pecadora frente de su conciencia, y prepara la coartada del pecado al subrayar su reciprocidad. Pero esta veleidosa mezcla de ética e individualismo fue, precisamente, el único consuelo que le quedó en el momento más lacerante de su vida. Un año antes de su muerte Lope cayó herido por sus propios filos: su hija Antonia Clara, la Antoñica que era la única compañía de su vejez, fue raptada por un Tenorio de carne y hueso, D. Cristóbal Tenorio. La reciprocidad del pecado está allí, de cuerpo presente, y no hay más consuelo que poetizar el perdón de su deshonra, como lo hace el anciano Lope en tonos de desesperada entereza, en su égloga Filis, en Huerto deshecho y en algún pasaje de La mayor virtud de un rey. Una vez más, en Lope, la literatura ha sido agorera de la vida, y por extraña taumaturgia ésta adquiere el contorno de la poesía; aquel peregrino concepto del honor de sus novelas ha cumplido su ciclo, y se adentra ahora en la vida como su único consuelo efectivo.

Queda todavía en pie el problema fundamental que encara Lope desde el momento en que se lanza a escribir estas novelitas: superar al Cervantes de las Novelas ejemplares. No es flaco problema, ya que esas obritas cervantinas forman un acabado muestrario de lo que dicho género había sido, era en ese momento, y hasta lo que podría llegar a ser, como indican los módulos extraordinarios del Coloquio de los perros, que no tuvo imitadores. Dentro del campo de la realidad artística acotado por Cervantes quedaba poco por hacer; fuera de ese campo no valía la pena hacer. Haz y envés del problema.

Lope le hace frente con esa inconmovible confianza en sí mismo que lo distinguió siempre. Por lo pronto dominará el escenario 
por un sistema de nutridísimas interrupciones en el relato que ha sido el rabiar de los críticos. A menudo éstas asumen la forma de apuntaciones críticas al progreso de la fabulación:

Realmente, señora Marcia, que cuando llego a esta carta y resolución de Laura, me falta aliento para proseguir lo que queda. ¡Oh imprudente mujer! ¡Oh mujer! Pero paréceme que me podrían decir lo que el ahorcado dijo en la escalera al que le ayudaba a morir, y sudaba mucho: "Pues, padre, no sudo yo, ¿y suda vuesa paternidad?" Si a Laura no se le da nada del deshonor y peligro, ¿para qué se fatiga el que sólo tiene obligación de contar lo que pasó?, que aunque parece novela debe de ser historia ( $L$ a prudente venganza).

Este ejemplo no tiene desperdicio. Obsérvese primero la forma en que se desdobla el autor en novelista y crítico. Se evidencia aquí algo de la actitud fundamental del Lope artista, que quiere ser autor, actor, espectador y crítico de su obra de arte. Antonio Machado, que tenía parecidos poderes de auto-abstracción a los de Lope, llegó a escribir en cierta ocasión: "Viví, dormí, soñé, y hasta he creado / un hombre que vigila / el sueño, algo mejor que lo soñado". Lope no le va en zaga a Machado, porque es Lope mismo quien vigila su propio sueño, donde él sueña que se está soñando. Esto es, en esencia y visto desde otro ángulo, lo que Leo Spitzer llamó Literarisierung des Lebens, que podría definirse como la necesidad perentoria en Lope de ser en toda ocasión el todo y la parte. Lo que evidencia la imposibilidad radical del Fénix de negarse la más mínima posibilidad, fuese vital o artística, y allí queda su descomunal vida-obra como testigo.

En el mismo ejemplo campea la ironía, que descose los lados de aquel "saco donde cabe todo", según definió Baroja a la novela. Es muy cierto que en la novela cabe de todo; por desdicha caben en ella hasta los elementos de su auto-destrucción, como casi a diario nos recuerdan las prensas. En las Novelas a Marcia Leonarda el elemento corrosivo y disolvente es la ironía, que fustiga a los personajes hasta la inhibición casi total. No hay, por parte de los personajes, ni movimiento, ni sentido de conducta, ni destino: sólo el albedrío del autor. "Déme licencia vuestra merced [le dice a Marcia Leonarda], para dejar este muerto, e irme con el famoso Guzmán, que ya comienza a ser bravo, por esos mundos adelante" (Guzmán el Bravo). La superioridad irónica de que hace gala en toda ocasión paraliza efectivamente la autonomía del personaje, quitándole, en consecuencia, la validez a la verdad artística. Es un aspecto de la técnica -o de la concepción de los fundamentos del arte-, que está emparentado de cerca con las funciones del gracioso en la comedia, ese nuevo tipo dramático que tanto se ufanaba Lope 
de haber inventado. Porque el gracioso está allí en la comedia para paralizar a su amo, con pinchazo irónico, en su carrera hacia el ideal. El gracioso niega la realidad de la ficción con su comentario irónico, y potencia así la dimensión irreal del teatro. En sus novelas, Lope mismo -eterna figura del donaire, al cabo-, se encarga de borrar la realidad de la ficción por idéntico uso de la ironía, y las novelas como tales se desdibujan en irrealidades veleidosas.

Este uso de la ironía revela como intención latente la de relativizar lo absoluto. La forma no discursiva de negar la validez de lo absoluto es la ironía, como bien sabe el gracioso de la comedia. Pero, en un sentido radical, es inimaginable un arte basado en relativismo, ya que todo arte tiene como punto de partida la aceptación de lo imaginario como real en términos absolutos y sin paliativos; un arte relativizado sería, en todo caso, un anti-arte, que crearía irrealidades y no realidades. Por eso es que ironizar equivale a irrealizar, como bien sabían los griegos, para quienes "ironía" significaba "disimulo", o sea "la realidad que no es". Al borde de este abismo del no-ser coloca Lope a la novela, no por el uso de la ironía -Cervantes fue maestro en él-, sino por su abuso. No se trata ya de crear nuevas realidades, sino más bien de destruirlas o relativizarlas, tanto monta, en la consecución de fraguar irrealidades.

En una época dedicada canónica y preceptivamente al principio de imitación (de la naturaleza, del arte), el novelar con irrealidades debe atribuirse a genialidad o a ineptitud. (Obsérvese, de pasada, que en cualquiera de los casos se zanja el espinoso problema de la emulación de las Novelas ejemplares). La irrealidad, a su vez, surge de la negación de lo real, que asume diversas formas: la ironía, las intromisiones del autor, su desdoblamiento en autor, crítico e interlocutor, las digresiones eruditísimas, los apartes de tono íntimo entre autor y Marcia Leonarda, etc. Todos estos aspectos son como desgarrones en el mundo tupido de la novela, que dijo Ortega, y por ellos se escapa la atmósfera de realidad. Son demasiados para coincidencia, por lo cual podemos descartar la posibilidad de que la irrealidad novelística sea producto de la ineptitud, solución que conviene subrayar pues más de un crítico se ha llamado a engaño al respecto.

Lope el realista, creador de irrealidades. Pero no va de paradoja. Se trata, más bien, de una aplicación consecuente, por parte de Lope, de un mismo modo de concebir los supuestos fundamentales de la obra literaria. Porque Lope concibe la novela en los mismos términos en que concibe el teatro: "Yo he pensado que tienen las novelas ios mismos preceptos que las comedias" (La desdicha por la honra). Y si indagamos un poco en la naturaleza del teatro veremos que es la metáfora suprema, suprema en cuanto es la metáfora visible. Actores y escenario representan una realidad que no es la 
propia, con lo que se concluye que el teatro es el gran demiurgo de irrealidades. Que Lope bien sabía esto sería decir una perogrullada, pero quizá no lo sea tanto agregar que por la creación del gracioso, el ironizador de la situación, Lope añadió nuevas dimensiones a lo irreal.

Consecuente con estas ideas, Lope desrealiza a los personajes de sus Novelas a Marcia Leonarda, hasta dejarlos en la pura metáfora de sí mismos: "Aquí confieso a vuestra merced, señora, que no sé, porque no me lo dijeron, cómo o por dónde vino a ser Felisardo no menos que bajá del Turco, que parece de los disfraces de las comedias" (La desdicha por la honra). Hasta la técnica de la mutación es dramática y no novelística, como bien sabe Lope. El personaje novelístico, además, se ve considerado como actor y no como agonista; su realidad es pura metáfora, o sea, es, fundamentalmente, pura irrealidad. Con esto, la ecuación inicial entre teatro y novela ha llegado a su última igualdad, y la novela queda convertida en instrumento de realización de lo irreal. Y esta sí es una estupenda paradoja conceptual, bien propia, por cierto, del más paradójico de los ingenios españoles.

En estas novelas de Lope la realidad no ha dejado más que la forma de su huida, según reza el hermoso verso de Juan Ramón. Pero bien visto, esto no es característica privativa ni de Lope ni de sus novelas. Es la nación toda que se ha quedado abrazando la forma de la huida de la realidad deseada, ya que el mundo se ha convertido, según verso de Góngora, "en tierra, en humo, en polvo, en sombra, en nada”. A lo que asentirá solemnemente Quevedo: "Y no hallé cosa en que poner los ojos / que no fusese recuerdo de la muerte". La crisis de la conciencia histórica de España ha entrado en su fase aguda y el español no acierta con la salida del mundo irreal y desmaterializado que lo rodea, para hallar el logro efectivo de su persona. Ya en 1552, Vasco Díaz Tanco había intitulado un libro suyo: Los seis aventureros de España, y cómo el uno va a las Indias, y el otro a Italia, y el otro a Flandes, y el otro está preso, y el otro anda en pleito, y el otro entra en religión. E cómo en España no hay más gente de estas seis personas sobredichas. Las posibilidades vitales se desvirtúan en guarismo, y la realidad plena se hace más inasequible. Quevedo escribirá a su amigo y tocayo, don Francisco de Oviedo:

Esto, señor don Francisco, no sé si se va acabando ni si se acabó. Dios sabe; que hay muchas cosas que pareciendo que existen y tienen ser, ya no son nada sino un vocablo y una figura.

La nación huye en masa de este mundo donde las cosas "ya no son nada", pero la búsqueda de lo sustantivo se resuelve en voca- 
blos y figuras. En esta huida desalentada de una realidad indeseable hay, sin embargo, un momento de descanso para el espíritu fatigado: las irrealidades escapistas del teatro, ese mundo de mentirijillas que en su escueto tablado puede brindar ilusiones de vida inhallables al pie de las candilejas. Así la comedia se eleva a la categoría del género nacional y caracteriza la literatura del siglo xvn. $\mathrm{Y}$ su característica impronta de irrealidad marcará para siempre estas novelas de Lope, escritas con la misma pluma que pergeñó mil quinientas comedias escapistas.

Juan Bautista Avalle-Arce 